\title{
NÓS E SUTURAS EM VÍDEO-CIRURGIA: ORIENTAÇÕES PRÁTICAS E TÉCNICAS
}

\author{
Nodes and sutures in video-surgery: technique and practice guidelines \\ Paulo César LEONARDI, Bruno ZILBERSTEIN, Carlos Eduardo JACOB, Osmar YAGI, Ivan CECCONELLO
}

Trabalho realizado no Serviço de Faculdade de Medicina da Universidade de São Paulo - FMUSP - São Paulo - SP - Brasil

DESCRITORES - Guias de prática clínica. Nós. Suturas.

\section{Correspondência: \\ Bruno Zilberstein, \\ e-mail: brunozilb@uol.com.br}

Fonte de financiamento: não há

Conflito de interesses: não há

Recebido para publicação: 16/06/2010

Aceito para publicação: 12/07/2010

HEADINGS - Practice guidelines. Knots. Suture.
RESUMO - Introdução - A realização de suturas e nós é das mais difíceis manobras cirúrgicas em videolaparoscopia. A habilidade de realizá-las durante os procedimentos videolaparoscópicos determinou grande expansão nas indicações laparoscópicas, bem como permitiu aos cirurgiões realizarem procedimentos de maior complexidade com mais segurança. O treinamento deve seguir as mesmas orientações do ensino de procedimentos básicos. Para tanto, meios podem ser encontrados no comércio ou serem confeccionados pelo cirurgião. Objetivo - Dar atualização aos nós e técnicas de suturas usadas em videocirurgia. Métodos - Descreve-se as técnicas mais práticas e usadas em nosso meio com figuras demonstrativas de como realizá-las. Conclusão - Existe uma lacuna importante da literatura científica na descrição e demonstração das diferentes técnicas de sutura em videocirurgia, como também existem muitas modalidades técnicas para a confecção de nós cirúrgicos. O seu conhecimento é importante para permitir ao cirurgião a escolha adequada nas diferentes situações e estratégias cirúrgicas existentes. A sistematização técnica dos nós e suturas em videocirurgia torna o procedimento mais fácil e seguro e deve ser cada vez mais divulgado.

ABSTRACT - Introduction - The completion of sutures and knots are the most difficult surgical maneuvers at laparoscopy. The ability to perform them during videolaparoscopy allowed surgeons to perform procedures of greater complexity with more security. The training should follow the same guidelines as the teaching of basic procedures. For this purpose, means may be found in trade or being prepared by a surgeon. Aim - To update techniques used in laparoscopic suturing. Methods Are described the techniques used with figures to demonstrate how to accomplish them. Conclusion - There is a significant gap in the scientific literature describing and illustrating the different suturing techniques in laparoscopic surgery, and there are many technical details for making surgery knots. Their knowledge is important to allow the surgeon to choose appropriately in different situations and surgical strategies what to use. The systematic technique of knots and sutures in laparoscopic surgery makes the procedure easier and safer and should be increasingly disseminated.

\section{INTRODUÇÃO}

A s realizações de suturas e nós são uma das mais difíceis manobras cirúrgicas em videocirurgia ${ }^{1}$. A habilidade de realizar suturas e nós durante os procedimentos videocirúrgicos determinou grande desenvolvimento nas indicações da cirurgia laparoscópica, bem como permitiu aos cirurgiões realizar procedimentos de maior complexidade com muito maior segurança. Seu conhecimento e treinamento devem seguir as mesmas orientações do ensino de procedimentos básicos, ou seja: treinos em simuladores, posteriormente em animais, para então somente passar a utilizá-los em operações avançadas².

É fundamental que o cirurgião e a equipe dominem uma ou mais técnicas para a realização confortável e segura dos procedimentos videocirúrgicos ${ }^{3}$. Não é claramente demonstrado, ou facilmente encontrado, na literatura que requisitos mínimos devem ser reconhecidos e realizados de rotina para que os nós e suturas sejam efetuados de maneira segura e com facilidade. $O$ conhecimento dos fios e agulhas adequados para videocirurgia é fundamental como em qualquer outra área cirúrgica. Porém nesta técnica, mais que em 
qualquer outra modalidade cirúrgica, estes detalhes são fundamentais. Desta forma constitui o objetivo deste artigo a apresentação e descrição das principais e mais utilizadas modalidades de realização de nós e suturas em videocirurgia, para facilitar e auxiliar a realização destes procedimentos ${ }^{4}$.

\section{Estágios Básicos da Sutura em videocirurgia}

São necessários três estágios para realização de nós em videocirurgia: 1) preparo do nó (configuração); 2) trabalhar ou desenhar o nó (formato); 3) apertar o nó (segurança).

Para que estes estágios sejam alcançados com segurança, conforto e eficiência são essenciais as seguintes etapas técnicas:

1 - utilização de pelo menos três portos;

2 - distanciamento adequado entre os trocárteres;

3 - as pinças (porta-agulha e contra porta-agulha) devem formar um ângulo de $60^{\circ}$ a $90^{\circ}$ entre si;

4 - fios e agulhas apropriados;

5 - boa condução da ótica pelo operador da câmera;

O número de portos mínimo para realização de nós e suturas é três em vista da necessidade de um ser para câmera, outro para realização do nó, quer seja pré realizado ou não, e o terceiro para o contra portaagulha ou para tração e fixação da estrutura na qual está se realizando a sutura. Devido à limitação espacial das manobras instrumentais, dificuldade da noção de profundidade (visão bidimensional) e campo visual limitado é fundamental ao correto posicionamento e distanciamento entre os trocárteres. Os portais devem ser colocados a uma distância apropriada (mínimo 10 $\mathrm{cm}$ ), para possibilitar aos trocárteres formarem um triângulo, preferencialmente, isóscele, com ângulo $60^{\circ}$ a $90^{\circ}$ entre as pinças e das pinças, com a mesma angulação, com o ponto onde se realiza a sutura, permitindo assim que a introdução das pinças crie um encontro ideal ao nível da sutura. Isto é essencial para que se tenha melhor dinâmica na passagem dos fios e movimentação entre as pinças, determinando maior facilidade e consequentemente menor tempo de execução.

Um dos princípios mais importantes de toda operação por videocirurgia - fundamental para correta realização das suturas -, é que todas as fases da sua realização devem ser feitas sob visão direta e o mais próximo possível5,6.

Para a realização do nó, geralmente são necessárias duas pinças ou dois porta-agulhas ou um portaagulha e uma pinça, que pode ser uma pinça curva tipo Maryland ou um contra porta-agulha. A tensão necessária ao nó deve ser dada sob visão direta, visto que a sensibilidade que o cirurgião tem é parcial e é feita através dos instrumentos utilizados. A aproximação tecidual requer que o ponto ideal seja realizado de maneira que os fios mantenham, juntamente com os tecidos, correta tensão. Ao contrário da operação convencional, na videocirurgia a força manual para unir duas ou mais estruturas é consideravelmente menor, devido ao sistema de alavancas que as pinças formam com a parede abdominal ou torácica. Além do mais, cada nó deve ser selecionado conforme cada caso, procedimento e colocação dos trocárteres.

Outro importante princípio é evitar a tensão exagerada dos fios quando aproximados. Isto se aplica particularmente às anastomoses de alças ou órgão ocos. A excessiva tensão na anastomose poderá propiciar isquemia dos tecidos com todas suas consequências. A eficiência de um nó ou sutura se relaciona à resistência à tensão de afastamento dos tecidos a serem aproximados. A primeira amarradura é a mais importante. Se esta ficar frouxa, as subsequentes não terão a configuração correta também, e consequentemente a sutura será inadequada ${ }^{7,8}$.

\section{Materiais para Suturas e Nós}

O uso de clipes metálicos, sem dúvida é a opção mais rápida e versátil para as ligaduras em videocirurgia, porém não são adequados em todas as situações. Os nós podem oferecer mais segurança e custo, geralmente, menor. É importante frisar que existem materiais de sutura mais adequados para uso em videocirurgia. Os fios de mais fácil utilização tem como características, o deslizamento fácil e "memória" fraca para não ficarem armados dentro da cavidade e evitar o travamento do primeiro meio nó. Também não devem afrouxar com facilidade, após a sua realização. Os fios mais utilizados em suturas por videolaparoscopia são os catgutes cromados, poliglactina $\left(\right.$ Vicryl $\left.^{\circledR}\right)$, PDS $^{\circledR}$, poliéster trançado e siliconizado (Ethibond ${ }^{\circledR}$ ) e eventualmente o algodão longo $(50 \mathrm{~cm})$. O comprimento dos fios para sutura intracórporea deve variar de 10, 15 a $25 \mathrm{~cm}$. Não devem ultrapassar tal comprimento, pois dificultam a realização dos nós favorecendo acidentes e/ou prolongando demasiadamente o tempo na realização dos mesmos. É importante frisar que o número médio de nós simples a serem aplicados varia de 3 a 5, de acordo com a natureza do fio que determinar o travamento e o deslizamento da sua superfície. A tensão dos bordos do tecido a ser suturado também exerce influência no número de nós a serem realizados. O primeiro nó pode ser duplo seguido de dois nós simples ou mesmo, se não houver grande tensão, serem realizados dois nós duplos em sentidos opostos ${ }^{9,10}$.

As agulhas a serem utilizadas deverão são todas do tipo pré-montadas e atraumáticas. Atualmente existem vários tipos de agulha para sutura intracorpórea, que têm utilidade para cada tipo de situação. Seu comprimento varia de 1 a $5 \mathrm{~cm}$, sendo o de $2,5 \mathrm{~cm}$, geralmente o mais empregado. Quanto à forma, as mais usadas são as do tipo reta, curva ou esqui, com comprimento de 1,5 a $3,0 \mathrm{~cm}$, para que sejam facilmente introduzidas pelos trocárteres de $10 \mathrm{~mm}$. As agulhas retas, que chegam a medir até $5,0 \mathrm{~cm}$ de comprimento, podem ser introduzidas de maneira transparietal através da 
parede da cavidade abordada.

Existem atualmente um bom número de modelos de porta-agulhas no mercado, variando conforme a sua "pega" ou "ponta" ou então quanto à empunhadura.

A pega anti derrapante com ponta de vídea e formato tradicional de $5 \mathrm{~mm}$ é o modelo mais comum. Entre os ginecologistas é usado com frequência o porta-agulha de Cook, que tem a ponta em gancho, semelhante a um bico de papagaio, que tem forte pega, com garra positiva, impedindo a rotação da agulha no momento de sua passagem pelos tecidos. Há no mercado um porta agulha denominado de "Endostich" ${ }^{\circledR}$ (Autosuture Company), que dispõe de dispositivo no cabo que, ao ser acionado, faz com que a agulha mude de posição automaticamente de uma para outra haste do aparelho, fazendo com que o fio passe pela borda a ser suturada. Outro porta agulha é o chamado "inteligente", onde a ponta tem uma canaleta inferior que permite o posicionamento adequado e correto da agulha na sua apreensão já dentro da cavidade, para a imediata passagem do ponto, qualquer que seja a sua posição inicial.

Quanto às empunhaduras, há as de $90^{\circ} \mathrm{com}$ mola ou cremalheira ou em arco como as usadas no portaagulha em gancho, ou as paralelas com cremalheiras ou arcos de pressão e ainda as do tipo Matthieu com cremalheira e arco. Geralmente a escolha é ditada por adaptação e capacitação de cada cirurgião, mais do que pela praticidade de um ou outro modelo.

\section{Tipos de Nós}

São inúmeros os tipos de nós cirúrgicos já descritos na prática cirúrgica, porém poucos são usados em videocirurgia devido as inerentes dificuldades da técnica. A sutura é dos procedimentos de coordenação motora mais complexo nesta via de acesso.

Os nós mais utilizados e as suas melhores indicações práticas são:

1 - endoalça (nó de Roeder);

2 - nó extracorpóreo (nó de Brooks);

3 - sutura intracorpórea;

4 - sutura com nó pré-realizado;

5 - nó de Clark;

6 - nó interno deslizante;

7 - nó interno de Topel.

1 - O nó de Roeder, ou endoalça, é importante artifício para ligadura de estruturas ou hemostasia em videocirurgia. Usa-se geralmente fio de categute com 25 centímetros de comprimento que corre no interior de um tubo de aço ou plástico de $5 \mathrm{~mm}$ de diâmetro com a extremidade distal afilada. Um nó é confeccionado nesta extremidade conforme figura 1 , formando uma alça de 5 a $10 \mathrm{~cm}$ de extensão. $\mathrm{Na}$ extremidade proximal é passada a extremidade da alça do fio que ao ser tracionada, após a laçada e estar bem posicionada, fecha esta alça de maneira firme ao tubo afilado que foi referido anteriormente e posicionado em torno da estrutura. Esta laçada necessita de redutor para sua introdução na cavidade peritoneal. Tal nó é útil para ligadura de coto apendicular ou do ducto cístico, muito calibrosos, onde a clipagem não é recomendada (Figura 1 e 2).

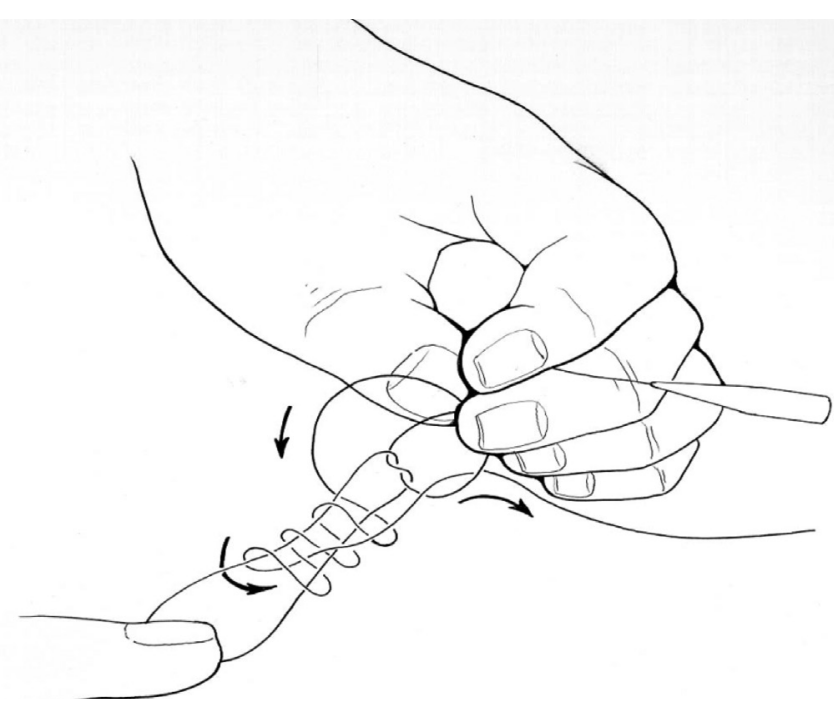

FIGURA 1 - Nó de Roeder

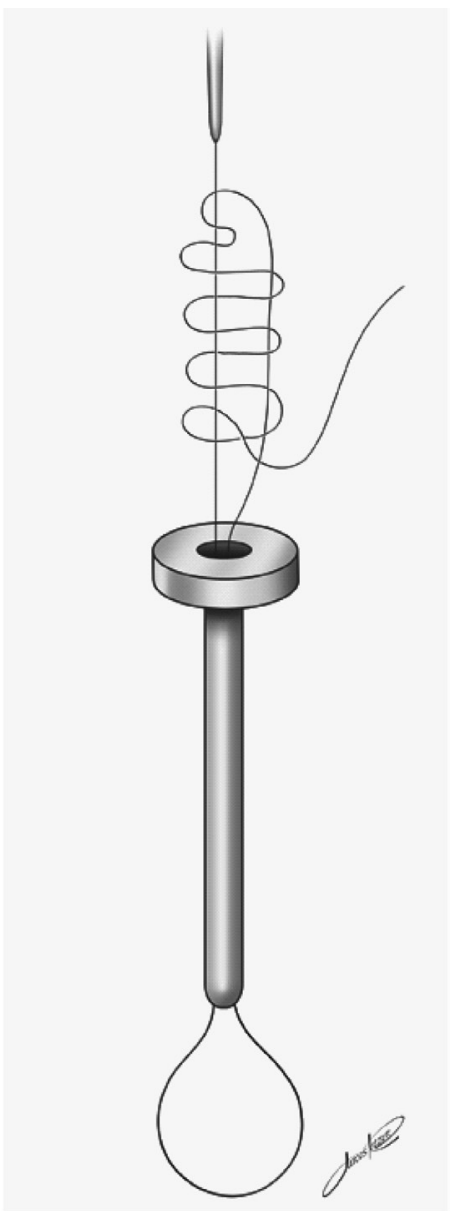

FIGURA 2 - Nó de Roeder passado através de reduto de 5 $\mathrm{mm}$ de diâmetro 
2 - O nó extracorpóreo é executado fora da cavidade, após introdução de fio longo de sutura agulhado, através de redutor de $5 \mathrm{~mm}$ para dentro da cavidade abdominal, deixando-se a extremidade distal deste fio fora da cavidade. Realiza-se então a passagem do fio longo agulhado na estrutura a ser suturada, traciona-se a extremidade agulhada para fora da cavidade. Então se seguram os dois cabos pelos dedos da mão esquerda e com a extremidade livre do fio se faz três revoluções envolvendo ambos cabos com alças do fio e se introduz a extremidade do fio na última alça logo acima dos dedos (técnica de Brooks). Esta é tracionada para a formação do nó e levado até a cavidade por guia metálico (condutor de nó) de extremidade afilada (Gâmbia) (Figura 3).

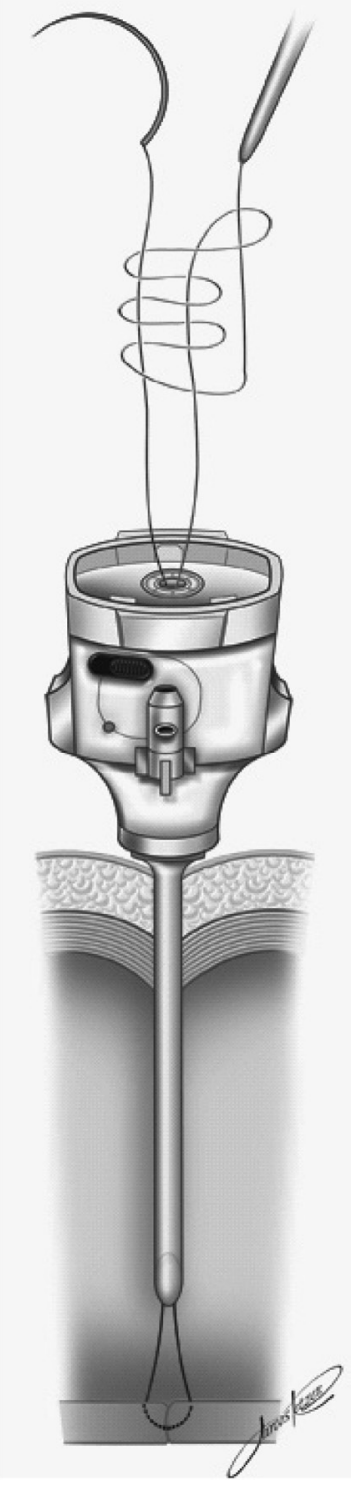

FIGURA 3 - Nó extracorpóreo

A sutura intracorpórea é realizada colocando-se na cavidade, fio agulhado como descrito anteriormente, do tipo sem memória (algodão, poliéster, seda etc), com comprimento de 10 a $20 \mathrm{~cm}$. Passa-se o fío nas estruturas a serem suturadas, deixando-se a extremidade da esquerda (agulhada) um pouco mais longa que a da direita, determinando a forma da letra $C$ ao fio passado nas estruturas. Com a extremidade longa do fio confeccionam-se duas voltas no porta-agulha, com o cuidado de não prender estas alças nas articulações do contra porta-agulha. A seguir traciona-se as duas extremidades do fio em sentidos opostos. Em seguida com o contra porta-agulha se cria uma letra $C$ ao contrário e se realizam duas voltas em torno do portaagulha. Tracionam-se ambas as extremidades, como anteriormente descrito, confeccionando o contra nó. È fundamental que o cirurgião seja adestrado a operar com ambas as mãos, deixando-se a condução da óptica aos cuidados de auxiliar hábil e que conheça as manobras para a realização do nó intracorpóreo, porque senão a sutura será trabalhosa e provavelmente defeituosa. Durante as laçadas a ponta da agulha deve ser deixada solta e voltada para cima para evitar ferimentos com a sua ponta. Nas suturas longas, devido aos inúmeros movimentos para dar entrada aos fios na cavidade, os nós e movimentos para secção e remoção dos mesmos recomenda-se sutura contínua onde se pode fixar as extremidades com pontos e/ou clipes facilitando os movimentos e tornando a síntese menos laboriosa e mais rápida (Figura 4).

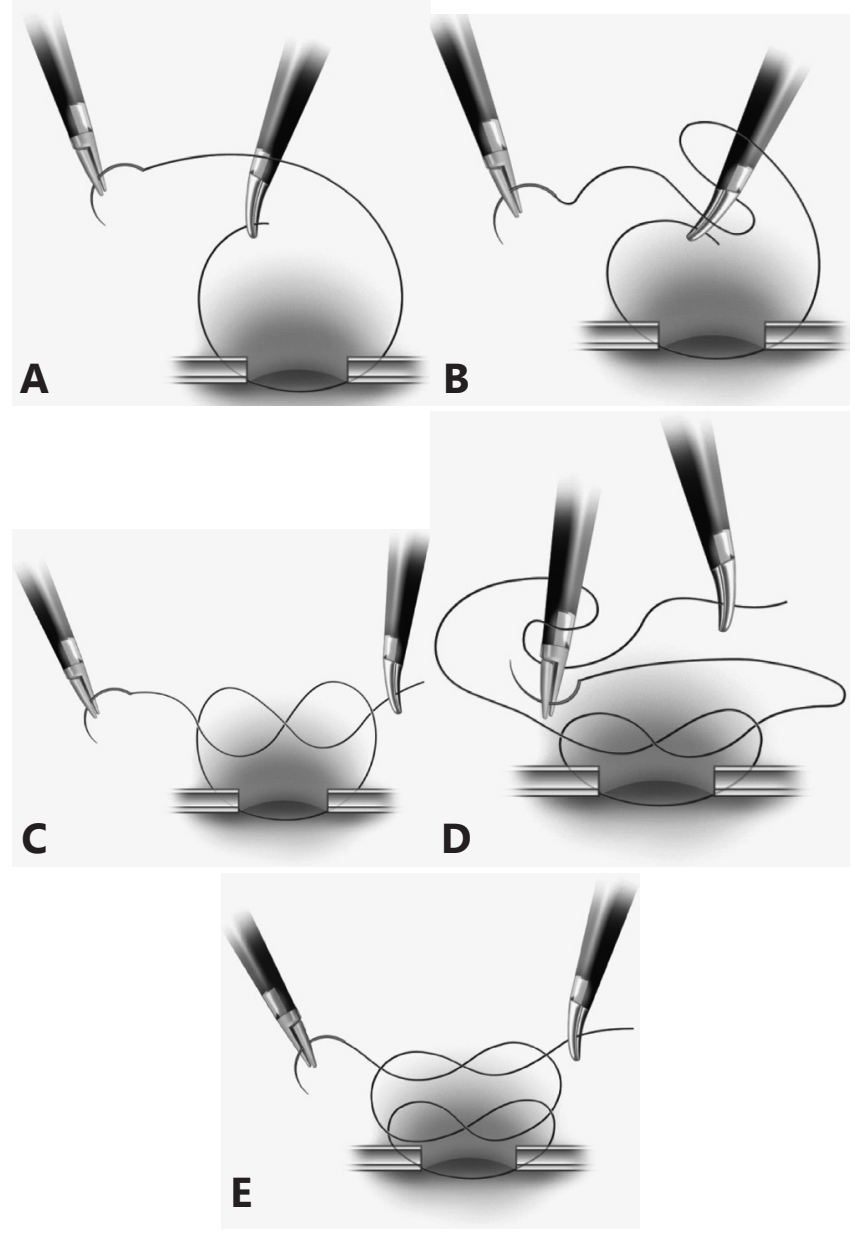

FIGURA 4 - Sutura intra-corpórea 
A sutura com nó pré-realizado consiste na realização prévia de uma alça na extremidade distal de um fio agulhado. Esta alça é montada de modo semelhante ao nó de Brooks, de forma que ao se tracionar o fio após suturar a estrutura desejada, este se fecha sobre si mesmo, dando a contenção necessária. Introduz-se o fio assim montado e dá-se o ponto ou sutura-se a estrutura desejada. Após a passagem do fio nas estruturas a serem suturadas, passa-se a agulha por dentro da alça, tracionando-se ambas as extremidades completando-se o primeiro nó de maneira rápida e fácil, sem as múltiplas manobras para a sua execução. (Figura 5). É um ponto útil para se iniciar uma sutura contínua.

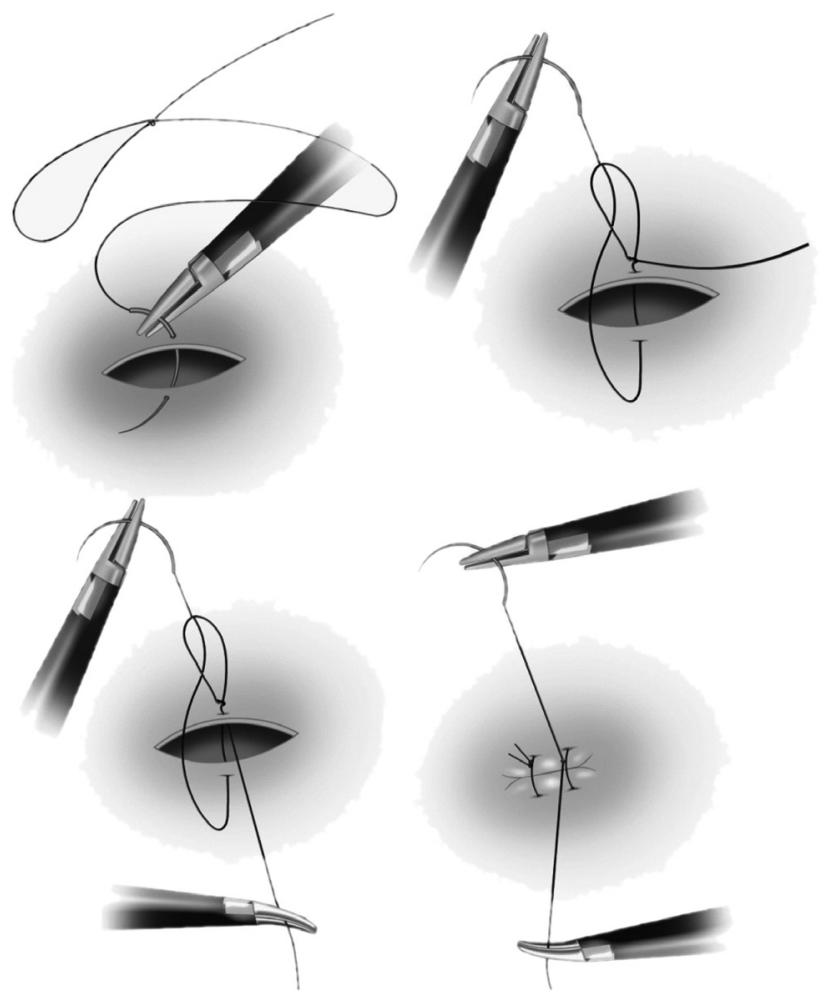

FIGURA 5 - Sutura com nó pré-realizado

O nó de Clarke, foi descrito em 1970, usando um dispositivo chamado de "empurrador de nó", que funciona como uma extensão do dedo do cirurgião. A sua realização se baseia na colocação da extremidade agulhada de um fio longo na cavidade; passagem deste nas estruturas a serem suturadas e a exteriorização da extremidade agulhada que é removida pelo mesmo trocarte ondejá se encontra e a extremidade distal. Então e realizado um meio nó duplo e ambas extremidades são gentilmente tracionadas por uma mão do cirurgião e com a outra, através do dispositivo especialmente criado para este fim, empurra-se o nó até alcançar a estrutura a ser suturada. Após isto, um segundo meio nó no mesmo sentido é aplicado para empurrar e fixar o primeiro, e o terceiro meio nó é aplicado para travar os anteriormente realizados (Figura 6).

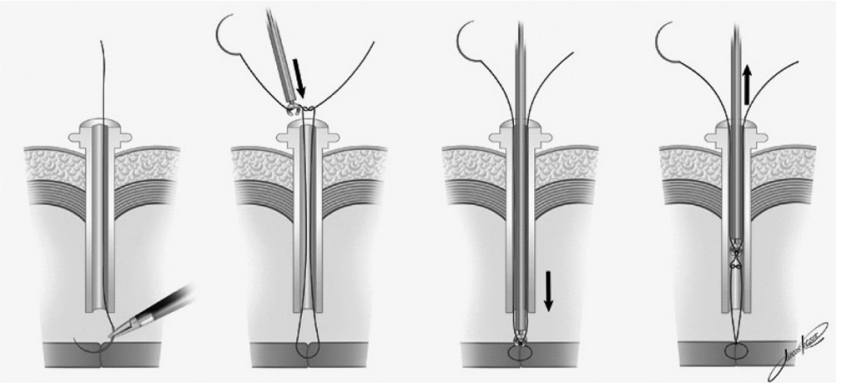

FIGURA 6 - Nó de Clarke

O nó interno deslizante é uma variedade da sutura intracorpórea. Após a realização de dois seminós, "frouxos" aprende-se um dos cabos acima e abaixo dos nós. Em seguida se ajusta o nó sobre este cabo e delizase até o tecido aonde será apertado. Os dois meios nós devem ser simples e ter o mesmo sentido para evitar que ele trave durante o deslizamento, não aproximando os bordos a serem suturados. Tal técnica é uma das práticas para suturar estruturas sob tensão e em profundidade em relação aos portos das pinças e ótica (Figura 7).

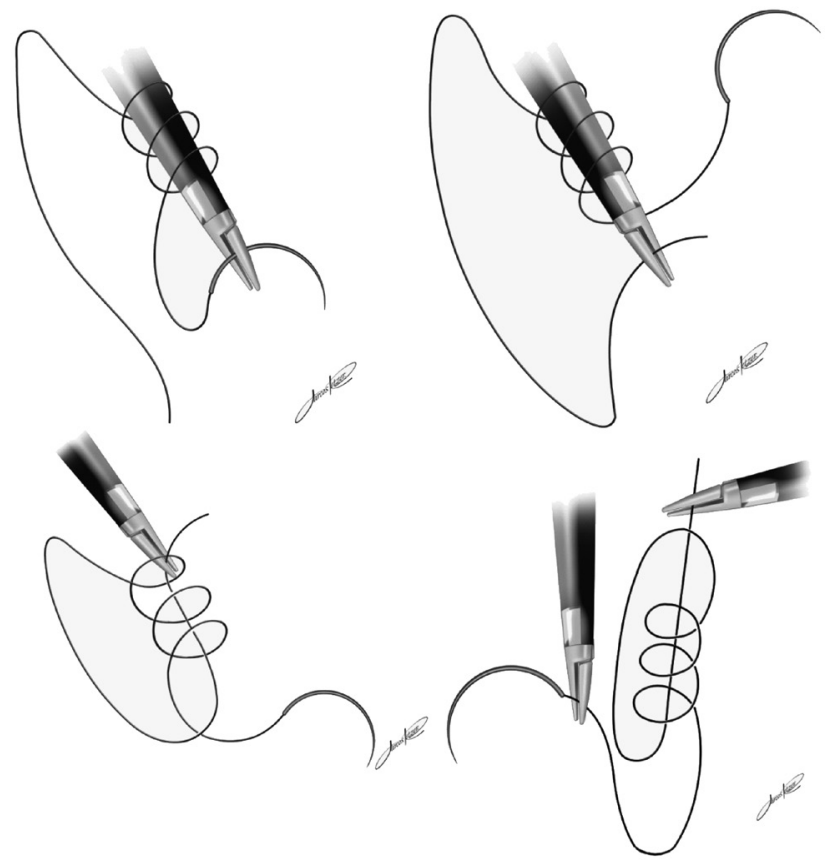

FIGURA 7 - Nó interno deslizante

O nó interno a Topel, consiste em apreender a extremidade proximal após a passagem do fio pelas suturas a serem aproximadas, cerca de $1 \mathrm{~cm}$ da agulha com o porta-agulha da mão esquerda e literalmente rola-se o porta-agulha sobre si próprio, criando duas ou três alças sobre o mesmo. Libera-se esta extremidade e apreende-se a extremidade distal com a ajuda do porta-agulha da mão direita, passando este cabo pelo interior das alças criadas durante a rolagem do porta-agulha da outra mão. Tal nó tem grande valia técnica em situações onde a profundidade for 
grande em relação à posição da ótica, ou quando os ângulos entre as pinças e ou o espaço no local da sutura forem inadequados ou menores que o correto, dificultando as manobras já descritas para realização de sutura intracorpórea ${ }^{11,12}$.

\section{CONCLUSÕES}

- Existe uma lacuna importante da literatura científica na descrição e demonstração das diferentes técnicas de sutura em videocirurgia.

- Existem muitas modalidades técnicas para a confecção de nós cirúrgicos em videocirurgia. O seu conhecimento é importante para permitir ao cirurgião a escolha adequada nas diferentes situações e estratégias cirúrgicas existentes.

- A sistematização técnica dos nós e suturas em videocirugia torna o procedimento mais fácil e seguro.

\section{REFERÊNCIAS}

1. Cushieri A.: Ductal stones: Pathology, clinical manifestations, laparoscopic extration tecniques and complications. Semin. Laparosc. Surg. 7: 246-261, 2000
2. Francis NK, Hanna GB, Cushieri A. Realiability of the advanced dundee endoscopic psychomotor tester for bimanual tasks. Arch Surg 2001;136:40-3.

3. Fredde T, Stock C, Tenner C, Budair Z, Salam YA, Rassweiller J. Geometric of laparoscopic suturing and knoting techiniques. J Am Assoc Gynecol Laparosc. 2002;13(3):191-8.

4. Nagai H, Araki S. Semiautomatic suturing device for laparoscoic surgery. Surg Endosc. 1999;13(2):191-3.

5. Nathanson LK, Easter DW, Cuschieri A. Ligation of the structures of the cystic pedicle during laparoscopic cholecystectomy. Am J Surg. 1991 Mar;161(3):350-4.

6. Paktin M, Isabel L. Ergomomics and lapaeroscopic general surgery in laparoscopic abdominal surgery. Editors: Graber JN, Pietrafitta JJ. Inc. 1993.

7. Reich $\mathrm{H}$. New techniques in advanced laparoscopic surgery. Baillieres Clin Obstet Gynaecol 1989;3:655-81.

8. Reich $\mathrm{H}$, Clarke HC, Sekel L. A Simple method for Ligating with straight and curved needles in operative laparoscopic. Obstet Gynecol 1992; 79:143-7.

9. Rosser JC. Laparoscopic suturing techniques In: Snider AP, Knoepfler DJ, Lee JW, Rosser JC, Eds. Advanced Endoscopic Workshop for Surgeons. 1991

10. Sedlack JD, Willians VM, Desimone J, Page D, Ghosh BC. Laparoscopic knot security. Surgery Laparosc Endosc. 1997; 45(4):262-5.

11. Topel HC. Endoscopic suturing and knot tying manual. Ethicon, Inc, 1997

12. Zucker KA. Surgical Laparoscopic. In: Louis, Quality Medical Publ. 1991 